\title{
Implementasi Sensor Water Level Dalam Sistem Pengatur Debit Air Di Pesawahan
}

\author{
Rini Suwartika Kusumadiarti ${ }^{\# 1,}$ Hadro Qodawi ${ }^{\# 2}$ \\ \# Program Studi Teknik Informatika Komputer, Politeknik Piksi Ganesha Bandung \\ $\frac{1 \text { rinisuwartika@gmail.com }}{2 \text { hadro.godawilodgmail.com }}$
}

\begin{abstract}
Information and Communication Technology (ICT) has an impact on all human activities today. The number of assistive media created by technology in agriculture has begun to emerge, apart from facilitating human work, the creation of these tools is considered to be able to shorten time and make harvests easier and faster. Many problems arise from farmers, especially in the problem of managing the waters for rice fields, one of which is when water does not flow from the springs, causing the rice fields to dry up and make rice and other plants die. The need for a technological innovation that functions as a water flow control system in rice field using a water level sensor that is applied with electronic programs and components, namely Arduino, is considered to be more effective, so that the irrigation system in paddy fields can be controlled and help solve the difficulties that occur.
\end{abstract}

Keywords : water Level Sensor, Arduino

Abstrak- Perkembangan Teknologi Informasi dan Komunikasi (TIK) yang sangat pesat memberikan pengaruh terhadap segala aktivitas manusia saat ini . Banyaknya media alat bantu yang tercipta dari teknologi dalm bidang pertanian mulai bermunculan, selain mempermudah pekerjaan manusia, terciptanya alat tersebut dianggap dapat mempersingkat waktu dan membuat hasil panen lebih mudah dan lebih cepat. Banyak permasalahan yang muncul dari para petani, khususnya dalam permasalah pengurusan perairan untuk pesawahan salah satunya adalah ketika air tidak mengalir dari mata air sehingga menyebabkan pesawahan akan mengering dan membuat tumbuhan padi dan tumbuhan lainnya akan mati. Perlunya sebuah inovasi teknologi yang berfungsi sebagai sistem pengatur debit air di sawahan menggunakan sensor water level yang di aplikasi dengan program dan komponen elektronika yaitu arduino dianggap akan lebih efektif, sehingga sistem pengairan di pesawahan dapat di control serta membantu menyelesaikan kesulitan yang terjadi.

Kata Kunci : sensor water level , Arduino

\section{PENDAHULUAN}

Seiring berjalannya waktu teknologi tumbuh begitu pesat, bahkan hal yang dulunya dianggap tidak mungkin sekarang dapat dilakukan dengan bantuan teknologi. Banyaknya media yang tercipta dari teknologi dalam bidang pertanian sangat lah banyak, selain mempermudah pekerjaan manusia, hal tersebut dapat mempersingkat waktu dan membuat hasil panen lebih mudah dan lebih cepat.

Saat ini beberapa lahan pertanian sudah menggunakan berbagai teknologi untuk mempermudah sistem pertanian dan pendapatan hasil pertanian, sistem kerja alat yang di ciptakan tentunya khusus untuk pertanian, dari mulai pesawahan hingga perkebunan. Pada sebagian besar negara yang mengkonsumsi beras sebagai makanan pokoknya, lahan pertanian merupakan media pertanian yang terpenting. Pengelolaan lahan pesawahan dicirikan oleh adanya pematang yang mengelilinginya dengan maksud untuk membatasi antara bidang lahan sawah satu dan bidang sawah lainnya. Pembuatan pematang sawah memiliki tujuan untuk mengatur kondisi air yang sesuai dengan kebutuhan, artinya mencegah keluar masuknya air yang berlebihan[1]. Karena air adalah kebutuhan pokok dari setiap media pertanian, selain matahari dan pupuk.

Pada kenyataannya munculah berbagai permasalahan dari para petani, khususnya dalam permasalah pengurusan perairan untuk pesawahan nya, salah satunya adalah ketika air tidak mengalir dari mata air karena seketika sistem pesawahan akan mengering dan membuat tumbuhan padi dan tumbuhan lainnya akan mati. Selain itu muncul juga permasalahan kurang nya perhatian dari para petani dalam menanggulangi sistem perairan untuk pertanian nya, dan terjadinya saling berebut akan jatah dari giliran air dari irigasi atau pun selokan. Ini sebabnya jika sistem pengairan tidak diatur sebaik mungkin, dan mungkin akan lebih buruk jika musim kemarau tiba. Tujuan Penelitian ini adalah mengetahui permasalahan yang terjadi pada lahan pesawahan terkait dengan pengelolaan debit air serta bagaimana implementasi penggunaan sensor water level 
sebagai simulasi pada pengelolaan air tersebut. Terkelolanya lahan pesawahan melalui sistem pengatur debit air diharapkan akan memudahkan para petani dalam hal mengelola sistem pengairan untuk pesawahan, selain itu juga dengan ada nya sistem teknologi ini akan mewujudkan terciptanya pengairan yang sama rata ketika musim kemarau tiba. Sehingga tidak akan ada perselisihan antara para petani yang berebut air.

\section{Tinjauan Pustaka}

\section{A. Arduino}

Arduino adalah sistem purnarupa elektronika (electronic prototyping platform) berbasis open-source yang fleksibel dan mudah digunakan baik dari sisi perangkat keras/hardware maupun perangkat lunak/software. Di luar itu, kekuatan utama arduino adalah jumlah pemakai yang sangat banyak sehingga tersedia pustaka kode program (code library) maupun modul pendukung (hardware support modules) dalam jumlah yang sangat banyak. Hal ini memudahkan para pemula untuk mengenal dunia mikrokontroler. Arduino didefinisikan sebagai sebuah platform elektronik yang open source, berbasis pada software dan hardware yang fleksibel dan mudah digunakan, yang ditujukan untuk seniman, desainer, hobbies dan setiap orang yang tertarik dalam membuat sebuah objek atau lingkungan yang interaktif [2].

Arduino sebagai sebuah platform komputasi fisik (Physical Computing) yang open source pada board input ouput sederhana, yang dimaksud dengan platform komputasi fisik disini adalah sebuah sistem fisik yang interaktif dengan penggunaan software dan hardware yang dapat mendeteksi dan merespon situasi dan kondisi.

Kelebihan arduino dari platform hardware mikrokontroller lain adalah:

1. IDE Arduino merupakan multiplatform, yang dapat dijalankan di berbagai sistem operasi, seperti Windows, Macintosh dan Linux.

2. IDE Arduino dibuat berdasarkan pada IDE Processing sederhana sehingga mudah digunakan.

3. Pemrograman Arduino menggunakan kabel yang terhubung dengan port USB bukan port serial. Fitur ini berguna karena banyak komputer sekarang ini tidak memiliki port serial.

4. Arduino adalah hardware dan software open source, pembaca bisa mendownload software dan gambar rangkaian arduino tanpa harus membayar ke pembuat arduino.

5. Biaya hardware cukup murah, sehingga tidak terlalu menakutkan untuk membuat kesalahan.

6. Proyek arduino ini dikembangkan dalam lingkungan pendidikan sehingga bagi pemula akan lebih cepat dan mudah mempelajarinya.

7. Memiliki begitu banyak pengguna dan komunitas di internet dapat membantu setiap kesulitan yang dihadapi terutama oleh programmer pemula.
IDE merupakan kependekan dari Integrated Developtment Enviroenment, atau secara bahasa mudahnya merupakan lingkungan terintegrasi yang digunakan untuk melakukan pengembangan. Disebut sebagai lingkungan karena melalui software inilah Arduino dilakukan pemrograman untuk melakukan fungsi-fungsi yang dibenamkan melalui sintaks pemrograman. Arduino menggunakan bahasa pemrograman sendiri yang menyerupai bahasa C. IC mikrokontroler Arduino telah ditanamkan suatu program bernama Bootlader yang berfungsi sebagai penengah antara compiler Arduino dengan mikrokontroler.

\section{B. Mikrokontroler}

"Sistem komputer memiliki tiga komponen utama yaitu unit pengolah pusat $(\mathrm{CPU}=$ Central Processing Unit $)$, media penyimpan dan sistem input/output (I/O Device) yang dihubungkan dengan perangkat luar [3]. CPU yang mengatur sistem kerja komputer mikro dibangun oleh sebuah mikroprosessor. Memori terdiri atas EEPROM untuk menyimpan program dan RAM untuk menyimpan data. Sistem I/O bisa dihubungkan dengan perangkat luar, misalnya sebuah speaker dan sebuah monitor bergantung pada aplikasinya. Jika CPU, Memori dan Sistem I/O dibuat dalam sebuah chip semikonduktor yang saling terhubung dengan baik, maka inilah yang dinamakan mikrokontroller".

\section{Water level Sensor}

Water level merupakan sensor yang berfungsi untuk mendeteksi ketinggian air dengan output analog kemudian diolah menggunakan mikrokontroler. Cara kerja sensor ini adalah pembacaan resistansi yang dihasilkan air yang mengenai garis lempengan pada sensor. Semakin banyak air yang mengenai lempengan tersebut, maka nilai resistansinya akan semakin kecil dan sebaliknya [4].

\section{Motor Servo}

Motor servo adalah sebuah perangkat atau aktuator putar (motor) yang dirancang dengan sistem kontrol umpan balik loop tertutup (servo), sehingga dapat di set-up atau di atur untuk menentukan dan memastikan posisi sudut dari poros output motor. motor servo merupakan perangkat yang terdiri dari motor DC, serangkaian gear, rangkaian kontrol dan potensiometer. Serangkaian gear yang melekat pada poros motor DC akan memperlambat putaran poros dan meningkatkan torsi motor servo, sedangkan potensiometer dengan perubahan resistansinya saat motor berputar berfungsi sebagai penentu batas posisi putaran poros motor servo.Penggunaan sistem kontrol loop tertutup pada motor servo berguna untuk mengontrol gerakan dan posisi akhir dari poros motor servo [5] .

\section{METODE PENELITIAN}

Penelitian yang dilakukan merupakan penelitian deskriptif dengan pendekatan kualitatif. Metode kualitatif merupakan metode penelitian yang digunakan untuk meneliti 
pada kondisi objek yang alami yang tidak berusaha untuk mencari pengaruh variabel tertentu terhadap variabel yang lain di mana peneliti adalah sebagai instrumen kunci.

Penelitian kualitatif meneliti secara objektif pernyataan subjektif para subjeknya. Tujuan penelitian kualitatif untuk memperoleh pengetahuan yang terungkap dari persepktif dalam para pelakunya, bukan menilai subjek \& latarnya dengan kriteria dari luar diri pelaku. Peneliti dipandu dengan catatan lapangan dan refleksi objektif dan subjektif peneliti saat mengumpulkan data. Penelitian kualitatif adalah penelitian yang lebih bersifat penelitian deskriptif dimana peneliti cenderung menggunakan pendekatan induktif.[6]

Penelitian ini dilaksanakan di Kp.pasanggrahan RT 01 RW 05 Desa Kersamanah Kecamatan Kersamanah Kabupaten Garut. Adapun waktu pelaksanaan penelitian pada bulan Januari - April 2020.

Adapun luas 1 petak sawah yang dijadikan objek penelitian adalah 50 meter $^{2}$ dan lahan sawah jumlah nya ada 5 petak sawah.

Alat yang digunakan terdiri dari Arduino MEGA, Water level sensor, Lampu LED Warna Merah, kuning dan hijau , Kabel Jamper Male Female \& Male Male, Buzzer, Motor Servo, dan Module Ethernet Shield.

Alur perancangan alat yang dilakukan dapat dilihat pada gambar 1:

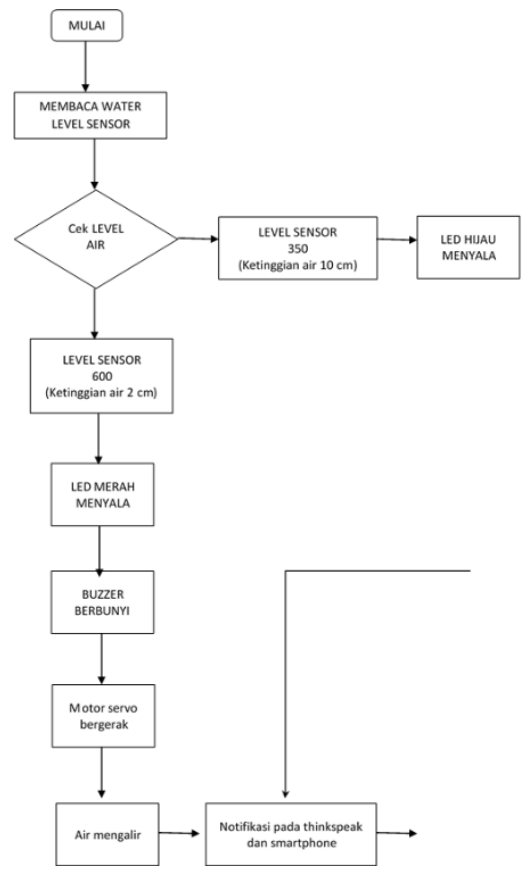

Gambar 1. Alur proses Sensor Water Level

\section{HASIL DAN PEMBAHASAN}

\section{A. Analisis Gambaran Objek penelitian}

Pesawahan adalah tanah yang digarap dan di aliri air untuk penanaman padi. Untuk keperluan ini pesawahan harus mamapu menyangga genangan air seperti yang berasal dari macam - macam sistem, dari mulai irigasi, selokan, mata air, hingga air hujan. Biasa nya para petani merawat pesawahan mereka yaitu dengan mengontrol sistem pengairan untuk kelangsungan tumbuhan padi subur dan tumbuh pada masa periode tertentu.

Selokan adalah media untuk mengalirkan air dari mata air sampai ke pesawahan dan lahan pertanian yang lain nya. Selokan adalah contoh sistem pengairan yang banyak di gunakan para petani untuk mengalirkan air dari sumber mata air ataupun yang berasal dari persilangan irigasi, dengan demikian yang di lakukan para petani adalah membuat sebuah sistem dimana mereka membagi jadwal dan harus mengatur secara manual pengairan yang mengalir ke sawah masing-masing, kebanyakan dari mereka melakukan sistem pembagian air tersebut tergantung dengan jam pembagian nya, dari jam pagi hingga malam hari.

Namun biasanya dengan menggunakan sistem manual ada pula persawahan yang di rugikan, contohnya adalah orang yang memiliki lahan persawahan yang dekat dengan sumber air maka lahan tersebut yang akan paling banyak mendapatkan air, namun lahan yang jauh dari sumber air biasa nya hanya seadanya air yang datang. Penjadwalan air yang berjalan dapat dilihat pada tabel 1 .

TABEL I.

Jadwal Pembagian Air Dan Jumlah Hasil Air Yang Didapatkan

\begin{tabular}{|c|c|c|c|c|c|}
\hline No & $\begin{array}{c}\text { Lahan } \\
\text { peswahan }\end{array}$ & $\begin{array}{c}\text { Jadwal } \\
\text { giliran }\end{array}$ & $\begin{array}{l}\text { Jumlah } \\
\text { debit air }\end{array}$ & $\begin{array}{l}\text { Perbedaan } \\
\text { jumlah debit } \\
\text { air }\end{array}$ & keterangan \\
\hline 1 & $\begin{array}{c}\text { Sawah } \\
\text { bagian } 1\end{array}$ & 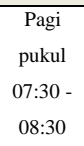 & $\begin{array}{c}15.000 \\
\text { Liter }\end{array}$ & $99 \%$ & $\begin{array}{c}\text { Air yang di dapatkan } \\
\text { masih banyak yaitu } 99 \%\end{array}$ \\
\hline 2 & $\begin{array}{c}\text { Sawah } \\
\text { bagian } 2\end{array}$ & $\begin{array}{c}\begin{array}{c}\text { Pagi } \\
\text { pukul } \\
09: 30- \\
10: 00\end{array}\end{array}$ & $\begin{array}{c}13.000 \\
\text { Liter }\end{array}$ & $87 \%$ & $\begin{array}{c}\text { Air yang di } \\
\text { dapatkan berkurang } 12 \%\end{array}$ \\
\hline 3 & $\begin{array}{c}\text { Sawah } \\
\text { bagian } 3\end{array}$ & $\begin{array}{c}\begin{array}{c}\text { Siang } \\
\text { pukul }\end{array} \\
10: 00- \\
12: 00\end{array}$ & $\begin{array}{c}12.000 \\
\text { Liter }\end{array}$ & $79 \%$ & $\begin{array}{l}\text { Air yang di dapatkan } \\
\text { berkurang } 10 \%\end{array}$ \\
\hline 4 & $\begin{array}{c}\text { Sawah } \\
\text { bagian } 4\end{array}$ & $\begin{array}{c}\begin{array}{c}\text { Siang } \\
\text { pukul }\end{array} \\
14: 00- \\
15: 00\end{array}$ & $\begin{array}{l}9.000 \\
\text { Liter }\end{array}$ & $65 \%$ & $\begin{array}{l}\text { Air yang di dapatkan lebih } \\
\text { berkurang } 12 \%\end{array}$ \\
\hline 5 & $\begin{array}{c}\text { Sawah } \\
\text { bagian } 5\end{array}$ & $\begin{array}{c}\begin{array}{c}\text { Sore } \\
\text { pukul } \\
17: 00- \\
17: 45\end{array}\end{array}$ & $\begin{array}{l}7.000 \\
\text { Liter }\end{array}$ & $59 \%$ & $\begin{array}{c}\text { Air yang di dapatkan lebih } \\
\text { berkurang dari sebelum } \\
\text { nya } 6 \%\end{array}$ \\
\hline
\end{tabular}

Dari tabel di atas dapat disimpulkan bahwa sistem pembagian air secara manual yang digunakan tidak efisien dalam menunjang kelangsungan pembagian debit air yang dibagikan dari pagi hingga sore hari, dan banyak permasalahan yang terjadi pada sistem pengairan yang ada. B. Analisis Batasan Sistem 
Dalam penelitian ini batasan sistem yang akan dirancang pada sistem alat pengatur debit air di pesawahan adalah sebagai berikut:

1. Alat yang dirancang akan berfungsi sebagai media pengganti sistem yang telah diterapkan sebelumnya.

2. Sistem yang diterapkan adalah yaitu dengan pemasangan sensor water level sensor yang berfungsi sebagai media untuk mengetahui dari jumlah debit air yang ada dan bisa di perhitungkan.

3. Alat dapat dijalankan dan berfungsi dengan baik jika telah di terapkan sesuai dengan gambaran alat yang di buat.

4. Pada bagian sistem informasi menggunakan media internet sebagai media antara alat dengan user

5. User dapat melihat setiap jumlah debit air dengan menggunakan media aplikasi yaitu dengan menggunakan web Thingspeak yang telah di sediakan guna menampilkan data dari setiap harinya berapa jumlah ketinggian air pada bendungan, dan aplikasi Thingspeak juga dapat diakses menggunakan semarphone dengan menggunakan App yang tersedia di app store semartphone. Jadi user dapat melihat jumlah dan ketinggian air juga dengan menggunakan semartphone nya jika tidak ingin membuka web Thingspeak.

6. Arduino MEGA sebagai pusat pengendalian alat dan Module Ethernet Shield adalah sebagai media dimana penghubung antara Arduino dengan web Thingspeak.

7. Bahasa pemrograman yang digunkan adalah bahasa pemrograman bahasa C Arduino.

8. Web Thingspeak merupakan open source IOT(Internet of Things), pada aplikasi ini user dapat mengupload hasil data dari sensor dengan menggunakan network internet, data yang di upload ke Thingspeak dapat data berupa pribadi maupun public.

\section{Analisis Masukan}

Analisis masukan dari rancangan alat pengatur debit air ini adalah water level sensor dimana sensor yang telah di pasang dan di hubungkan dengan Arduino MEGA dimana sensor tersebut telah di beri program pada mikrokontroler Arduino MEGA, sensor tersebut memiliki tingkat kesulitan pada kalibrasi hasil data yang tidak selalu menunjukan hasil kalibrasi yang akurat sesuai dengan perintah dalam program.

\section{Analisis Keluaran}

Tahapan ini berfungsi untuk mengetahui keluaran apa saja yang dihasilkan dari alat yang dibangun yaitu :

1. BUZZER berfungsi untuk mengeluarkan suara pada saat indikator jika air di bendungan sudah keadaan tinggi, maka buzzer akan mengeluarkan suara sebagai indikatornya.

2. LED yang berfungsi sebagai indikator bahwa keadaan air menunjukan rendah, sedang dan tinggi. Jadi pada rancangan alat ini banyak menggunakan LED sebagai indikator anataralin LED berwarna merah, kuning dan hijau, fungsi dari LED berwarna merah adalah sebagai indikator jika keadaan air di bendungan dan di sawah sudah menunjukan keadaan rendah, kemudian LED berwarna kuning menunjukan keadaan di bendungan keadaan air sedang, dan LED berwarna hijau sebgai indikator keadaan jika di bendungan dan di sawah menunjukan keadaan air dalam keadaan tinggi atau full.

3. Web Thingspeak

Web Thingspeak merupakan open source IOT(Internet of Things), hasil data dari sensor akan muncul di Thingspeak yaitu dengan menggambarkan tinggi dan rendah nya intensitas air yang terdikteksi oleh sensor.

\section{E. Analisa Kebutuhan Komponen}

1. Perangkat Keras

Untuk merancang alat pengatur debit air di pesawahan memerlukan perangkat keras atau Hardware sebagai berikut:

TABEL II.

Kebutuhan Hardware

\begin{tabular}{|c|c|c|c|}
\hline No & Nama Komponen & Jumlah & $\begin{array}{c}\text { Gambar } \\
\text { Komponen }\end{array}$ \\
\hline 1 & Arduino MEGA & 1 buah & \\
\hline 2 & Water level sensor & 5 buah & \\
\hline 3 & $\begin{array}{l}\text { Lampu } \\
\text { LED } \\
\text { Warna } \\
\text { Merah }\end{array}$ & 5 buah & \\
\hline 4 & $\begin{array}{l}\text { Lampu } \\
\text { LED } \\
\text { Warna } \\
\text { Hijau }\end{array}$ & 5 buah & \\
\hline 5 & $\begin{array}{l}\text { Kabel Jamper } \\
\text { Male Female \& } \\
\text { Male Male }\end{array}$ & 5 Set & \\
\hline 6 & Buzzer & 1 buah & \\
\hline 7 & Motor Servo & 5 buah & \\
\hline 8 & $\begin{array}{l}\text { LED warna } \\
\text { kuning }\end{array}$ & $\begin{array}{c}1 \\
\text { buah }\end{array}$ & \\
\hline
\end{tabular}

TABEL III.

Kebutuhan Hardware 


\begin{tabular}{|c|c|c|c|}
\hline No & Nama Komponen & Jumlah & $\begin{array}{l}\text { Gambar } \\
\text { Komponen }\end{array}$ \\
\hline 9 & $\begin{array}{l}\text { Kabel Konektor } \\
\text { USB }\end{array}$ & 1 buah & \\
\hline 10 & $\begin{array}{l}\text { Module } \\
\text { Ethernet Shield }\end{array}$ & 1 buah & \\
\hline 11 & Board project & 2 buah & \\
\hline 12 & Akrilik & 2 set & \\
\hline 13 & Lem Bakar & 5 set & \\
\hline 15 & Kabel UTP & 1 set & \\
\hline
\end{tabular}

2. Perangkat Lunak

Perangkat lunak yang dibutuhkan untuk membuat program alat tersebut adalah IDE Arduino. Untuk menulis program pada papan arduino dibutuhkan Aplikasi Arduino IDE (Integrated Development Environment).

F. Prinsip Kerja

Prinsip kerja dari sistem alat pengatur debit air di pesawahan adalah sebagai berikut ini:

1. Water Level Sensor

Water level sensor sebagai media pengatur air, water level sensor pengatur debit air di bendungan dan di pesawahan.

2. Motor servo

Motor servo sebagai penggerak pintu air, sistem kerja motor servo adalah ketika keadaan air sedang rendah dan lampu indikator LED warna merah menyala maka motor servo akan bergerak $90^{\circ}$, namun jika keadaan air sudah tinggi dan indikator lampu LED hijau menyala maka motor servo akan bergerak $160^{\circ}$.

3. Mikrokontroler Arduino MEGA

Arduino mega sebagai pengendali semua mekanisme alat yang ada, dari perintah menggerakan servo hingga menghidupkan Buzzer dan LED semua di lakukan oleh Arduino mega.

\section{Buzzer}

Buzzer sebagai media untuk mengeluarkan suara seperti hal nya bel atau alarm, Buzzer bekerja ketika keadaan air di bendungan dalam keadaan sudah mencapai ketinggian yang di tentukan, jadi jika keadaan air di bendungan sudah tinggi maka Buzzer akan menyala atau (HIGH).

5. LED

LED sebagai media indikator ketika keadaan air sedang dalam keadaan intensitas tinggi, sedang, dan rendah, jadi sistem kerja LED ini adalah jika keadaan air rendah maka lampu led berwarna merah akan menyala, kemudian jika keadaan air menunjukan keadaan sedang maka lampu led kuning akan menyala dan led hijau dan merah akan mati. Selanjutnya jika keadaan intensitas air sudah mencapi ketinggian batas yang telah di tentukan maka lampu led berwarna hijau akan menyala dan lampu led merah dan hijau akan mati.

6. Module Ethernet Shield

Module Ethernet Shield sebagai media penghubung antara Arduino mega dengan menggunakan kabel UTP dan RJ45 agar terhubung dengan laptop atau PC dan dengan web Thingspeak ataupun dengan App semarphone yang di sudah di download di app store yang saling terkoneksi satu sama lain menggunakan Api key yang berada pada Thingspeak. Jadi web Thingspeak adalah sebagai media untuk menampilkan hasil data dari sensor agar bisa mengetahui tingkat intensitas ketinggian air dan rendah nya air pada bendungan dan sawah.

7. Kabel UTP dan RJ45

Kabel UTP dan RJ45 sebagai penghubung antara Ethernet Shield dengan laptop atau PC, dengan menggunakan kabel UTP, jenis kabel UTP Straight. Kabel Straight ini berfungsi menghubungkan 2 device yang berda, seperti Ethernet Shield dan laptop termasuk 2 device yang berbeda, dan kita hanya perlu mensetting IP Address agar Ethernet Shield bisa terkoneksi dengan Internet melalui PC atau laptop.

Perancangan sistem alat pengatur debit air di pesawahan berbasis Arduino mega dan terhubung dengan ThinkSpeak. Berikut ini adalah rangkaiannya:

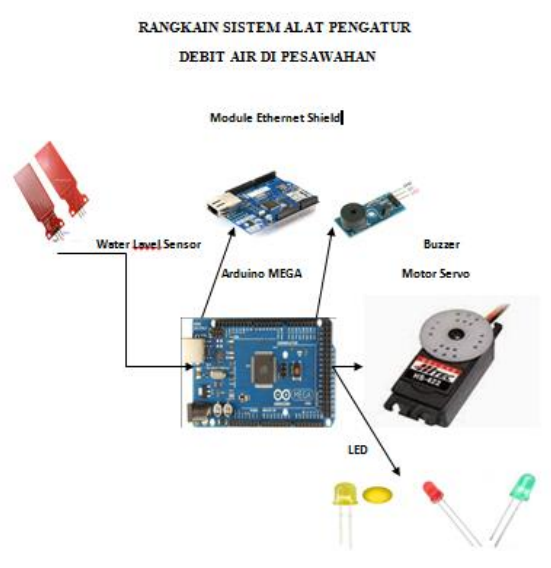


Gambar 2. Rangkaian Sistem Pengatur Debit Air

Keterangan:

1. Water level sensor terhubung dengan pin $\mathrm{A} 0-\mathrm{A} 4$, dan terdapat pin VCC dan GND pada water lavel sensor. VCC di hubungkan pada 5V pada Arduino MEGA, dan GND dihubungkan ke GND di Arduino MEGA, dan juga sebagai OUTPUT yang berfungsi untuk mencari hasil kalibrasi dari tinggi rendah nya air.

2. Kemudian menghubungkan pin digital dari pin2 hingga pin18.

3. Menghubungkan servo ke Arduino MEGA dari pin2 pin6, dengan masing - masing pin dalam motor servo terdapat pinVCC dan GND, dimana untuk VCC di hubungkan ke pin Arduino MEGA di pin 5V, dan GND di hubungkan ke GND.

4. Menghubungkan Buzzer ke pin 18 pada Arduino MEGA dan terhubung dengan GND.

5. Pasangkan LED warna merah, kuning, hijau dari mulai pin 7 - pin 17.

Pasangkan module Ethernet Shield dengan Arduino Mega, kemudian pasangkan Ethernet Shield dengan laptop dengan menggunakan kabel UTP dan RJ45.

G. Cara Kerja Teknologi

Cara kerja teknologi alat ini adalah dengan berdasarkan dengan blok dan sekema dan juga rangkaian, terdapat sensor water level sebagai pendeteksi ketinggian air, dan motor servo sebagai penggerak pintu air otomatis sesuai dengan program dan tergantung dengan hasil sensor water level yang mendeteksi jumlah atau tinggi nya air.

Semua fungsi diatas akan berjalan jika semua dirangkai sesuai dengan skema dan alat yang sudah diprogram melalui software Arduino uno IDE dan dirangkai diberi daya. Setelah dirangkai diberi daya dan program telah berhasil diupload, semua komponen atau perangkat akan menjalankan fungsinya dengan program Arduino Mega dan Ethernet Shield.

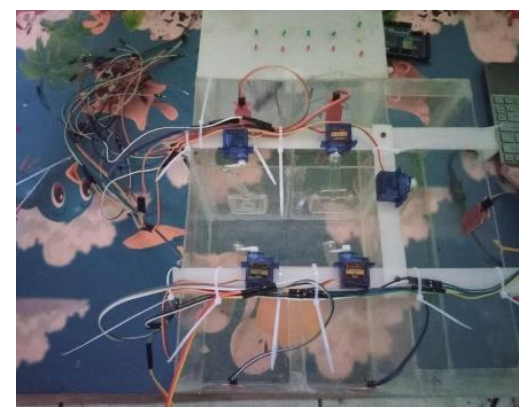

Gambar 3. Komponen Utama sedang dirangkai dan uji coba

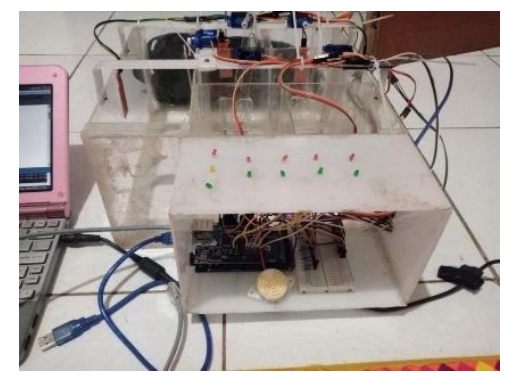

Gambar 4. Komponen sedang di uji coba tampak bagian depan

1. Hubungkan Arduino Uno pada USB Laptop, LED Merah pada Arduino Mega bertanda apabila terhubung ke aliran listrik dan menyalakan komponen lain yang terhubung ke Arduino Mega.

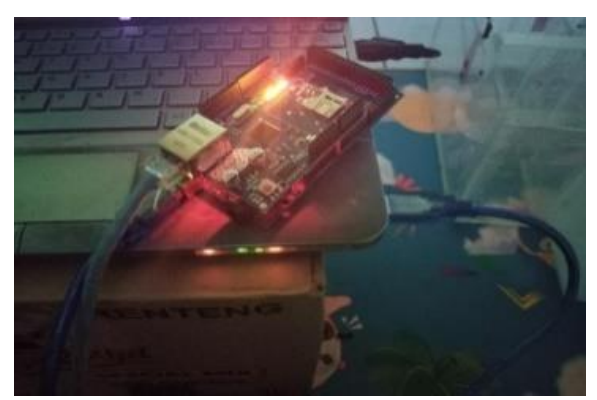

Gambar 5 Arduino Mega dan Ethernet terhubung dengan USB ke Laptop 2. Masukan koding pada Arduino IDE pada saat Arduino Mega terhubung ke USB laptop.

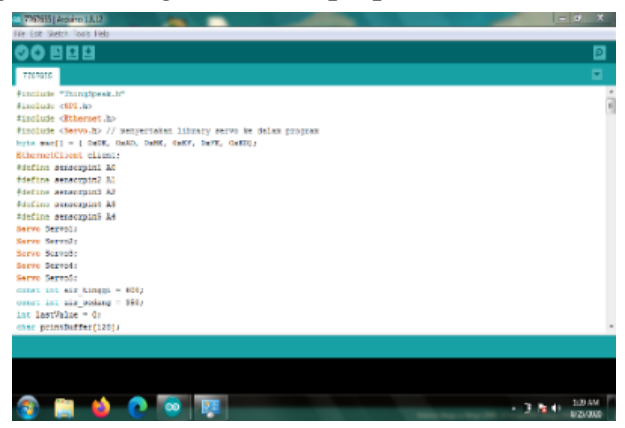

Gambar 6. Membuat Program Pada IDE Arduino Mega

Berikut Pemgrograman Arduino Mega dan Ethernet Shiled

Coding alat pengatur debit air di pesawahan

\#include "ThingSpeak.h"

\#include $\langle$ SPI.h>

\#include <Ethernet.h>

\#include <Servo.h> // menyertakan library servo ke dalam program

byte mac []$=\{0 x D E, O x A D, 0 x B E, O x E F, O x F E, O x E D\}$;

EthernetClient client;

\#define sensorpin1 AO

\#define sensorpin 2 A1

\#define sensorpin3 A2

\#define sensorpin4 A3

\#define sensorpin5 A4

Servo Servol;

Servo Servo2;

Servo Servo3;

Servo Servo4:

Servo Servo5;

const int air tinggi $=600$;

const int air_sedang $=350$

int lastValue $=0$;

char printBuffer [128];

int led1_rendah=7; //inisial led1 masuk pin 2 
int led2_sedang=8; $\quad$ //inisial led2 masuk pin 3 int led3_tinggi=9; $\quad$ //inisial led3 masuk pin 4

int led4=10; $\quad$ //inisial led4 masuk pin 5

int led5=11; //inisial led5 masuk pin 6

int led6=12; $\quad$ //inisial led6 masuk pin 7

int led7=13; $\quad$ //inisial led 7 masuk pin 8

int led8=14; $\quad$ //inisial led8 masuk pin 9

int led $9=15 ; \quad$ //inisial led 9 masuk pin 10

int led10=16; //inisial led10 masuk pin 11

int led11=17; //inisial led11 masuk pin 12

int Buzzer=20,

unsigned long myChannelNumber $=1092880$;

const char * myWriteAPIKey = "4AHJG7N7C1ULFPWF";

void setup ()

// put your setup code here, to run once:

Servol.attach(2);

Servo2.attach (3);

Servo3.attach $(4)$

Servo4.attach (5);

Servo5.attach(6);

pinMode(sensorpin1,INPUT); //sensor suara sebagai INPUT

pinMode(sensorpin2,INPUT);

pinMode(sensorpin3,INPUT);

pinMode (sensorpin4,INPUT)

pinMode(sensorpin5,INPUT);

pinMode(led1 rendah,OUTPUT); //led1 sebagai OUTPUT

pinMode(led2_sedang,OUTPUT); I/led2 sebagai OUTPUT

pinMode(led3_tinggi,OUTPUT); //led2 sebagai OUTPUT

pinMode(led4,OUTPUT); //led2 sebagai OUTPUT

pinMode(led5,OUTPUT); //led2 sebagai OUTPUT

pinMode(led6,OUTPUT); //led2 sebagai OUTPUT

pinMode(led7,OUTPUT); //led2 sebagai OUTPUT

pinMode(led8,OUTPUT); //led2 sebagai OUTPUT

pinMode(led9,OUTPUT); /lled2 sebagai OUTPUT

pinMode(led10,OUTPUT); I/led2 sebagai OUTPUT

pinMode(led11,OUTPUT); //led2 sebagai OUTPUT

pinMode(Buzzer,OUTPUT);//Menentukan Buzzer sebagai Output

Serial.begin(9600);

Ethernet.begin(mac)

ThingSpeak.begin(client);

Serial.begin(9600); //Serial komunikasi arduino

void loop()

step1();

delay(1000);

step2();

delay (1000),

step3();

delay(1000);

step4();

delay (1000)

step5();

delay (1000),

void step1()

int value = analogRead $($ sensorpin1 $) ; \quad$ //membaca sensor ketinggian

Serial.println(value); $\quad$ I/menampilkan nilai sensor ketinggian air di serial monitor

delay(1000);

//waktu $1000 \mathrm{~ms}$

if ( sensorpin 1$) ;$

if value $=0$ ) i

Serial.println("Keadaan dari sensor ke-1"),

Serial.println("Status");

Serial.println("Ketinggian Air : Kosong" );

digitalWrite(led1_rendah,LOW);

digitalWrite(led2 sedang, $L O W$ );
digitalWrite(led3_tinggi,LOW);

digitalWrite(Buzzer, LOW);

Servol.write(90); // Turn Servo Ke kanan 135 degrees delay(1000);

else if (value $>0 \& \&$ value $<=$ air_sedang)

Serial.println("Status"),

Serial.println("Ketinggian Air : Rendah" );

digitalWrite(led1_rendah, $\mathrm{HIGH}$ ).

digitalWrite(led2_sedang,LOW);

digitalWrite(led3_tinggi, $L O W$ );

digitalWrite(Buzzer,LOW);

\}

else if (value $>$ air_sedang $\& \&$ value $<=$ air tinggi)

Serial.println("Status"),

Serial.println("Ketinggian Air : Sedang")

digitalWrite(led1_rendah,LOW);

digitalWrite(led2 sedang, $H I G H$ ),

digitalWrite(led3_tinggi,LOW);

digitalWrite(Buzzer,LOW);

else if (value > air_tinggi

Serial.println("Status"),

Serial.println("Ketinggian Air : Tinggi" ),

digitalWrite(led1_rendah,LOW);

digitalWrite(led2_sedang,LOW);

digitalWrite(led3 tinggi,HIGH);

digitalWrite(Buzzer,HIGH);

Servol.write(180); // Turn Servo ke kiri 45 degrees

delay(1000);

l

if value $==0)$

Serial.println("Status"),

Serial.println("Ketinggian Air : Kosong" );

digitalWrite(led1_rendah, $L O W)$;

digitalWrite(led2_sedang,LOW);

digitalWrite(led3 tinggi,LOW)

digitalWrite(Buzzer,LOW);

Servol.write(70); // Turn Servo Ke kanan 135 degrees

delay(1000);

j

delay(1000);

\}

void step2()\{

int value= analogRead (sensorpin2); I/membaca sensor ketinggian air

Serial.println(value); $\quad$ //menampilkan nilai sensor ketinggian air

di serial monitor

delay(1000);

//waktu $1000 \mathrm{~ms}$

if ( sensorpin 2$)$ :

if (value >500) ?

//jika nilai sensor lebih dari 500

Serial.println("Keadaan dari sensor ke-2");

digitalWrite(led4,HIGH); $\quad$ //led1 nyala

digitalWrite(led5,LOW); $\quad$ //led2 mati

Serial.println("Status"),

Serial.println("Monitor sensor 2");

Serial.println("ketinggian air penuh");

monitor bahwa air penuh

Servo2.write(70); // Turn Servo ke posisi center position (90 degrees)

else\{ I/jika tidak

digitalWrite(led4,LOW); I/led1 mati

digitalWrite(led5,HIGH); $\quad$ //led2 nyala

Serial.println("Status"), 
Serial.println("status air kosong"); //menampilkan ke serial monitor bahwa air kosong

Servo2.write(195); // Turn Servo ke kiri 45 degrees delay(1000);

\}

,

void step3()\{

int value = analogRead (sensorpin3); I/membaca sensor ketinggian air

Serial.println(value); $\quad$ //menampilkan nilai sensor ketinggian air

di serial monitor

delay(1000);

//waktu $1000 \mathrm{~ms}$

( sensorpin 3$) ;$

if (value >500) \{

//jika nilai sensor lebih dari 500

Serial.println("Keadaan dari sensor ke-5");

digitalWrite(led6,HIGH); $\quad$ //led1 nyala

digitalWrite(led7,LOW); $\quad$ //led2 mati

Serial.println("Status");

Serial.println("Monitor sensor 3");

Serial.println("Ketinggian air penuh"); I I/menampilkan ke serial monitor bahwa air penuh

Servo3.write(180); // Turn Servo ke posisi center position (90 degrees

delay (1000);

else\{ I/jika tidak

digitalWrite(led6,LOW); //led1 mati

digitalWrite(led7,HIGH); $\quad$ //led2 nyala

Serial.println("Status");

Serial.println("Status air kosong"); I/menampilkan ke serial monitor bahwa air kosong

Servo3.write(70); // Turn Servo ke kiri 45 degrees

delay(1000);

\}

\}

void step4()\{

int value $=$ analogRead $($ sensorpin 4$) ; \quad$ //membaca sensor ketinggian air

Serial.println(value); $\quad$ //menampilkan nilai sensor ketinggian air

di serial monitor

delay(1000);

/waktu $1000 \mathrm{~ms}$

if ( sensorpin 4$)$;

if (value >500) \{

//jika nilai sensor lebih dari 500

Serial.println("Keadaan dari sensor ke-4");

digitalWrite(led8,HIGH); $\quad$ /lled1 nyala

digitalWrite(led9,LOW); $\quad$ //led2 mati

Serial.println("Status");

Serial.println("Monitor sensor 4");

Serial.println("Ketinggian air penuh"); I/menampilkan ke serial monitor bahwa air penuh

Servo4.write(180); // Turn Servo ke posisi center position (90 degrees)

delay(1000);

//jika tidak

digitalWrite(led8,LOW); //led1 mati

digitalWrite(led $9, \mathrm{HIGH}) ; \quad$ //led2 nyala

Serial.println("Status");

Serial.println("Status air kosong"); I/menampilkan ke serial monitor bahwa air kosong

Servo4.write(70); // Turn Servo ke kiri 45 degrees

delay(1000);

\}

?

void step 5() int value = analogRead (sensorpin5); I/membaca sensor ketinggian air

Serial.println(value); $\quad$ //menampilkan nilai sensor ketinggian air di serial monitor

delay(1000);

if (sensorpin 5$) ;\{$

if (value >500)\{//jika nilai sensor lebih dari 500

Serial.println("Keadaan dari sensor ke-5");

digitalWrite(led10,HIGH); I/led1 nyala

digitalWrite(led11,LOW); //led2 mati

Serial.println("Status");

Serial.println("Monitor sensor 5");

Serial.println("Ketinggian air penuh"); I/menampilkan ke serial monitor bahwa air penuh

Servo5.write(195); // Turn Servo ke posisi center position (90 degrees)

else\{ //jika tidak

digitalWrite(led10,LOW); I/led1 mati

digitalWrite(led11,HIGH); $\quad$ //led2 nyala

Serial.println("Status");

Serial.println("Status air kosong"); //menampilkan ke serial monitor bahwa air kosong

Servo5.write(70; // Turn Servo ke kiri 45 degrees delay(1000); \}

3. Setelah koding done compiling rangkai semua komponen dan setelah itu upload koding tersebut.

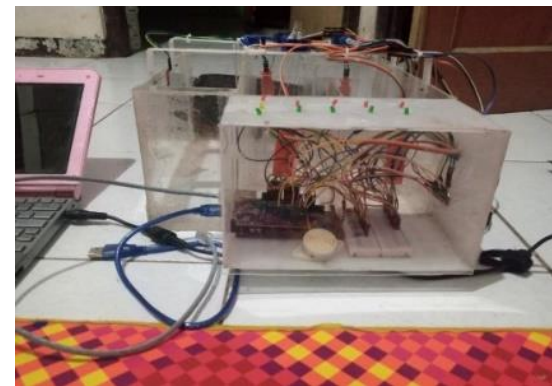

Gambar 7 Rangkaian Alat Setelah dirangkai pada body Box tampak depan

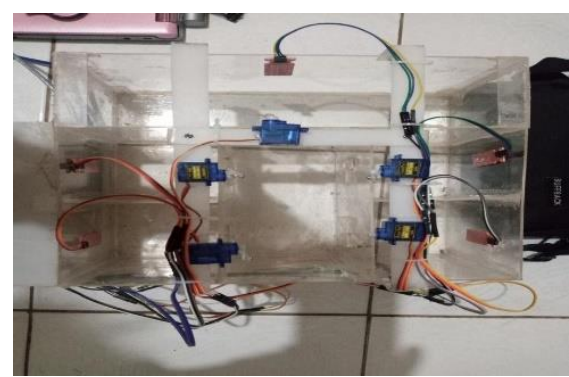

Gambar 8.Rangkaian Alat Setelah dirangkai pada body Box tampak atas

4. Melakukan setting internet pada laptop.

a. Masuk ke bagian Network dan Internet pada laptop, kemudian klik view network status and tasks 


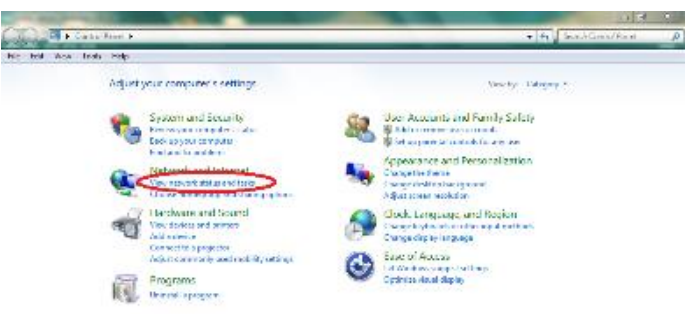

6)

Gambar 9. Setting Internet dan Network pada laptop

b. Kemudian akan muncul tampilan dibawah, pastikan laptop terhubung dengan internet, dan pastikan Ethernet terhubung dengan laptop

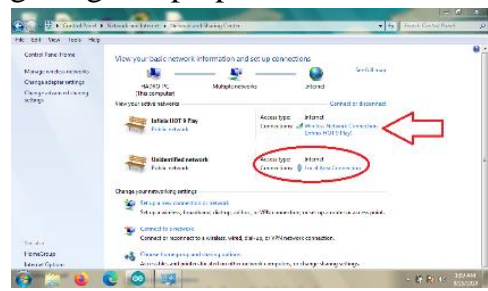

Gambar 10. Setting Internet dan Ethernet pada laptop

c. Setelah semua terhubung, maka langkah selanjutnya pilih dan klik inter protocol seperti pada gambar di bawah ini.

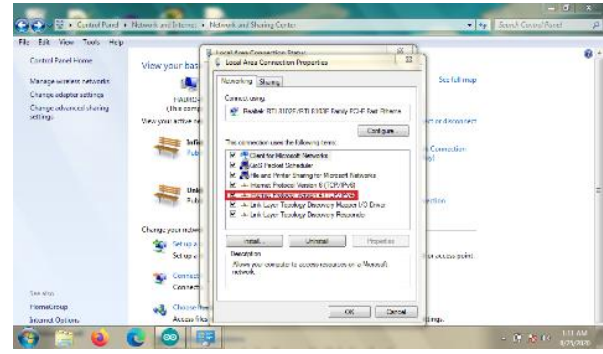

Gambar 11. Setting Internet protocol Ethernet

d. Maka akan muncul General seperti pada gambar dibawah, dan pastikan alamat IP Address di setting sesuai dengan koneksi yang ada pada Ethernet.

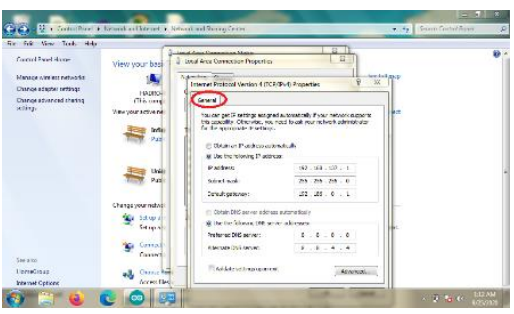

Gambar 12. Setting Internet protocol Ethernet IP Address

5. Setelah semua beres dan Ethenet sudah terkoneksi dengan internet, maka selanjutnya masuk ke web, atau Mozila Firefox dan di bagian pencarian tulis kan Thingspeak web. Kemudian login terlebih dahulu seperti gambar dibawah yang bertanda merah, kemudian klik dan lakukan pengisian Email dan Password.

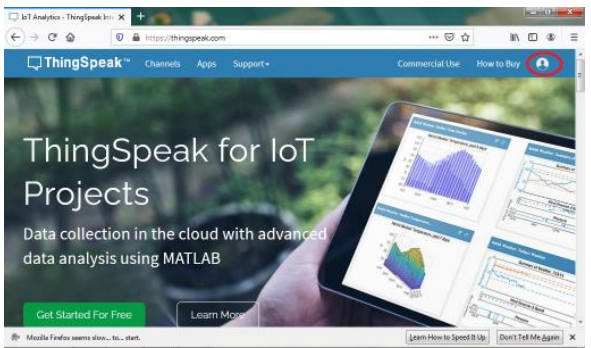

Gambar 13 Melakukan pencarian Thingspeak dan melakukan login

6. Kemudian setelah login di lakukan, maka buatlah channeles baru dalam Thingspeak, setalah membuat chanel baru maka channeles yang kita buat sudah bisa terkoneksi dengan Ethenet seperti pada gambar.

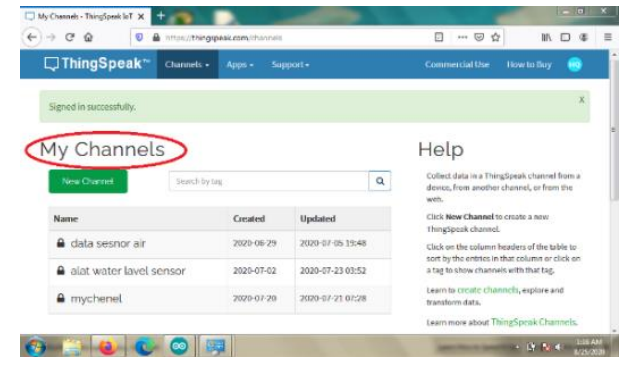

Gambar 14 Membuat Channels baru di Thingspeak

7. Setelah semua selesai, yang terakhir melihat hasil data yang ada pada filed yang kita buat tadi, kemudian kita akan melihat hasil data dari sensor water level di thingspeak seperti pada gambar.

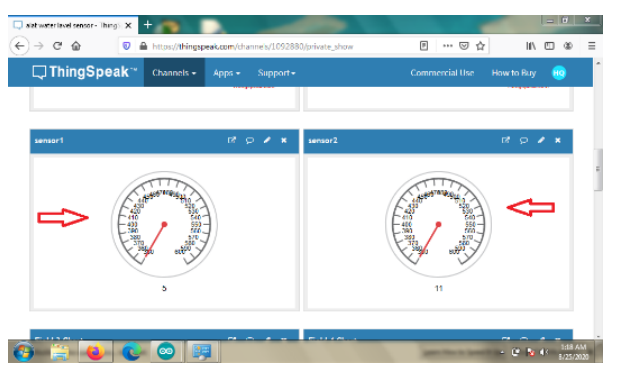

Gambar 15 Hasil data yang muncul dari sensor ke thingspeak di web server

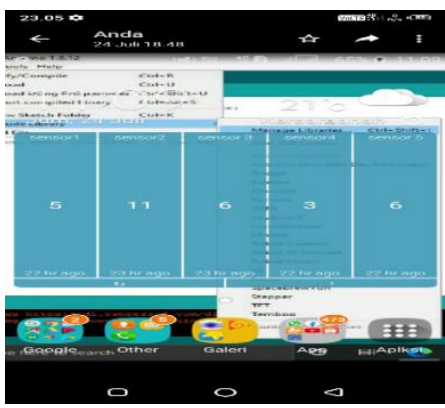


Gambar 16 Hasil data yang muncul dari sensor ke thingspeak pada Smartphone

\section{H. Model Simulasi Pengujian}

Pengujian di lakukan dengan melihat hasil dari kalibrasi sensor water level yang di pasang pada box, jika air tinggi atau rendah motor servo akan berputar sesuai dengan program yang telah di uji, kemudian jika ketinggian air rendah, sedang dan tinggi maka LED akan menyala, dimana dibagian penampungan air, jika keadaan air tinggi maka Buzzer pun akan berbunyi, bahwa itu menandakan air dalam keadaan tinggi.

TABEL III.

Simulasi Pengujian Alat

\begin{tabular}{|c|c|c|c|c|c|}
\hline No & $\begin{array}{c}\text { Keadaan } \\
\text { Sensor } \\
\text { water } \\
\text { level }\end{array}$ & $\begin{array}{l}\text { Motor } \\
\text { servo } \\
\text { berputar }\end{array}$ & $\begin{array}{l}\text { Keadaan } \\
\text { Led }\end{array}$ & $\begin{array}{l}\text { Buzzer } \\
\text { (Alarm) }\end{array}$ & $\begin{array}{l}\text { Tampilan } \\
\text { Thingspeak }\end{array}$ \\
\hline 1. & $\begin{array}{c}\text { sensor } \\
1 \text { level } \\
<350 \\
\text { sensor } \\
1 \text { level } \\
>400 \\
\text { sensor } \\
1 \text { level } \\
>600\end{array}$ & $\begin{array}{c}70^{\circ} \\
180^{\circ}\end{array}$ & $\begin{array}{c}\text { Merah On } \\
\text { Kuning On } \\
\text { Hijau On }\end{array}$ & Buzzer On & $\begin{array}{l}\text { L:350 } \\
\text { L:400 } \\
\text { L:600 }\end{array}$ \\
\hline 2. & $\begin{array}{c}\text { sensor } \\
2 \text { level } \\
<350 \\
\text { sensor } \\
2 \text { level } \\
>450 \\
\text { sensor } \\
2 \text { level } \\
>500\end{array}$ & $\begin{array}{c}70^{\circ} \\
180^{\circ}\end{array}$ & $\begin{array}{c}\text { Merah On } \\
\text { Hijau On }\end{array}$ & Buzzer Off & $\begin{array}{l}\mathrm{L}: 350 \\
\mathrm{~L}: 450 \\
\mathrm{~L}: 500\end{array}$ \\
\hline 3. & $\begin{array}{c}\text { sensor } \\
3 \text { level } \\
<350 \\
\text { sensor } \\
3 \text { level } \\
>480 \\
\text { sensor } \\
3 \text { level } \\
>600\end{array}$ & $\begin{array}{c}70^{\circ} \\
180^{\circ}\end{array}$ & $\begin{array}{c}\text { Merah On } \\
\text { Hijau On }\end{array}$ & Buzzer Off & $\begin{array}{l}\mathrm{L}: 350 \\
\mathrm{~L}: 480 \\
\mathrm{~L} 600\end{array}$ \\
\hline 4. & $\begin{array}{c}\text { sensor } \\
4 \text { level } \\
<350 \\
\text { sensor } \\
4 \text { level } \\
>500 \\
\text { sensor } \\
4 \text { level } \\
>600\end{array}$ & $\begin{array}{c}70^{\circ} \\
180^{\circ}\end{array}$ & $\begin{array}{c}\text { Merah On } \\
\text { Hijau On }\end{array}$ & Buzzer Of & $\begin{array}{l}\mathrm{L}: 350 \\
\mathrm{~L}: 500 \\
\mathrm{~L}: 600\end{array}$ \\
\hline 5. & $\begin{array}{l}\text { sensor } 5 \\
\text { level } \\
<350\end{array}$ & $\begin{array}{c}70^{\circ} \\
180^{\circ}\end{array}$ & $\begin{array}{c}\text { Merah On } \\
\text { Hijau On }\end{array}$ & Buzzer Of & $\begin{array}{l}\mathrm{L}: 350 \\
\mathrm{~L}: 430 \\
\mathrm{~L}: 600\end{array}$ \\
\hline
\end{tabular}

\begin{tabular}{|l|l|l|l|l|}
\hline sensor 5 & & & & \\
level & & & \\
$>430$ & & & & \\
sensor 5 & & & & \\
level & & & & \\
$>600$ & & & & \\
\hline
\end{tabular}

Dari tabel diatas dapat kita ketahui bahwa menunjukan perbedaan hasil data dari beberapa sensor water level, dimana diatas menunjukan bahwa tampilan pada thingspeak di beri lambang huruf (L), dimana (L) adalah (LEVEL). Jadi pada data diatas menunjukan hasil diantaranya sebagai berikut:

1. Sensor ke -1 menunjukan bahwa rendah, sedang dan tinggi hasil kalibrasi air pada sensor, jumlah keadaan rendah air adalah $=350$, maka motor servo akan berputar $70^{\circ}$ kemudian indikator led merah akan ON, maka hasil yang muncul di thingspeak adalah 350, namun jika hasil air $=400$, maka led berwarna kuning akan ON, dan tampil di thingspeak, kemudian hasil air $=600$, led hijau ON dan Buzzer akan ON dan servo akan berputar $180^{\circ}$ maka tampil di thingspeak 600.

2. Sensor ke -2 menunjukan hasil air $=350$ maka servo berputar $70^{\circ}$ dan led merah ON, kemudian hasil air $=500$ maka servo berputar $180^{\circ}$ dan led hijau ON, kemudian hasil kedua nya akan muncul di thingspeak.

3. Sensor ke -3 menunjukan hasil air rendah $=350$ maka servo berputar $70^{\circ}$ dan led merah ON, kemudian hasil air tinggi $=600$ maka servo berputar $180^{\circ}$ dan led hijau ON, kemudian hasil kedua nya akan muncul di thingspeak.

4. Sensor ke -4 menunjukan hasil rendah air $=350$ maka servo berputar $70^{\circ}$ dan led merah $\mathrm{ON}$, kemudian hasil tinggi air $=600$ maka servo berputar $180^{\circ}$ dan led hijau ON, kemudian hasil kedua nya akan muncul di thingspeak.

5. Sensor ke -5 menunjukan hasil rendah air $=350$ maka servo berputar $70^{\circ}$ dan led merah ON, kemudian hasil tinggi air $=600$ maka servo berputar $180^{\circ}$ dan led hijau ON, kemudian hasil kedua nya akan muncul di thingspeak.

\section{KESIMPULAN}

Berdasarkan penelitian dan pegujian yang dilakukan maka dapat di ambil beberapa kesimpulan sebagai berikut:

1. Sistem pembagian air secara manual yang digunakan sebelumnya dianggap tidak efisien dalam menunjang kelangsungan pembagian debit air yang dibagikan dari pagi hingga sore hari, hal ini terbukti dengan adanya perbedaan jumlah debit air pada objek penelitian, penurunan debit air antara 1 petak sawah dengan sawah berikutnya sebesar 2000 liter.

2. Melalui perancangan sistem pengatur debit air menggunakan sensor water level yang berfungsi sebagai pendeteksi jumlah ketinggian air, motor servo sebagai penggerak pintu air, LED sebagai media indikator untuk 
menunjukan tinggi rendah nya air, dan Buzzer sebagai notifikasi jika keadaan air tinggi di bagian bendungan maka Buzzer akan berbunyi, serta yang paling utama adalah Mikrokontroler Arduino Mega sebagai pengendali menunjukan bahwa jumlah debit air menjadi stabil, petak sawah yang memiliki debit air kurang akan diairi melalui pintu pintu air secara otomatis

3. Melalui bantuan aplikasi thinkspeak pengontrolan jumlah debit air di bak control pusat menjadi lebih efisien, karena jika jumlah debit air bak control berkurang maka akan ada notifikasi pemberitahuan melalui smartphone ataupun melalui buzzer / alarm yang berbunyi.

Diharapkan dengan adanya alat sistem pengatur debit air ini dapat memudahkan para petani dalam mengatur dan memantau persawahan nya.

DAFTAR PUSTAKA

[1] A. Setiawan, "PERANCANGAN SISTEM MONITORING AIR SAWAH MENGGUNAKAN KONSEP INTERNET OF THINGS BERBASIS ANDROID.” University of Technology Yogyakarta, 2020.

[2] Y. A. Badamasi, "The working principle of an Arduino," in 2014 11th international conference on electronics, computer and computation (ICECCO), 2014, hal. 1-4.

[3] S. J. Sokop, D. J. Mamahit, dan S. R. U. A. Sompie, "Trainer periferal antarmuka berbasis mikrokontroler arduino uno," J. Tek. Elektro Dan Komput., vol. 5, no. 3, hal. 13-23, 2016.

[4] B. N. Getu dan H. A. Attia, "Automatic water level sensor and controller system," in 2016 5th International Conference on Electronic Devices, Systems and Applications (ICEDSA), 2016, hal. $1-4$.

[5] Y. M. Dinata, Arduino Itu Pintar. Elex Media Komputindo, 2016.

[6] A. Anggito dan J. Setiawan, Metodologi penelitian kualitatif. CV Jejak (Jejak Publisher), 2018. 